\title{
EXPERIMENTAL AND NUMERICAL STUDY OF CONVECTIVE HOT AIR DRYING OF CIRCULAR SHAPED CASSAVA PELLETS
}

\author{
Azaka Onyemazuwa Andrew, Enibe Sammuel Ogbonna, Achebe Chinonso Hubert, Nwadike Emmanuel Chinagorom \\ Department of Mechanical Engineering, \\ Nnamdi Azikiwe University, Awka, Anambra State, Nigeria
}

\begin{abstract}
This study is aimed at the experimental predictions and numerical modeling of moisture diffusivity in a circular shaped cassava pellets during convective drying, using samples of TMS 30572 cassava species. Using a circular mold of radius $16 \mathrm{~mm}$ and height $10 \mathrm{~mm}$ designed for this purpose, the Cassava tubers were hand peeled and cut into slabs. The drying tests were conducted using a hot air-convective dryer that can dry samples weighing from 0 to $100 \mathrm{~g}$. The response of the drying curve or the drying kinetic depends on the applied drying conditions. The dryer was set at different heater temperatures of $150^{\circ} \mathrm{C}$, $140^{\circ} \mathrm{C}, 130^{\circ} \mathrm{C}, 120^{\circ} \mathrm{C}$ and $110^{\circ} \mathrm{C}$ which gave corresponding hot air temperatures of $81^{\circ} \mathrm{C}, 78^{\circ} \mathrm{C}, 75^{\circ} \mathrm{C}, 70^{\circ} \mathrm{C}$, and $66^{\circ} \mathrm{C}$ respectively. The hot air velocity was kept constant at $4 \mathrm{~m} / \mathrm{s}$. The drying dynamics dictated by Fick's second law for a 2-dimensional element as influenced by both initial condition and Neumann Boundary condition was used to define the mass transfer process, by assuming isotropic behavior of the samples. The comparison between the experimental results and the proposed analytical solutions of the equation of diffusion represented by Fick's law, applied to 2-dimensional analysis for a finite shape, allows determination of the values of the diffusion coefficient. The diffusivity of the circular samples were determined to be in range of $3.1467 \times 10^{9}-1.4759 \times 10^{9} \mathrm{~m}^{2} \mathrm{~s}^{-1}$, and described using a $3^{\text {rd }}$ order polynomial equation $\left(y=0.0001 x^{3}-0.0487 x^{2}-6.0254 x+246.05\right)$
\end{abstract} as a function of air temperature with the value of $R^{2}=$ 0.9402. The diffusivity plots clearly explain that the moisture diffusivity of cassava pellets can be expressed as a function of temperature using a 3rd order polynomial equation. These results show that the finite element method can predict cassava drying with a high degree of accuracy such that the costly case-by-case empirical approach, which is based on linear or non-linear regression analysis for parameter estimation, can be avoided. The study could provide theoretical bases for equipment design and process optimization for hot air drying of Cassava pellets.
Keywords - Finite Element, Convective Drying, Moisture Diffusivity, Cassava Pellets.

\section{INTRODUCTION}

The temporal and spatial variations of moisture content of agricultural products during drying are governed by the laws of diffusion. Diffusion mechanics are expressed in partial differential equations (PDE) and then can be solved using the Finite Element (FE) Method. This has been the research practice for decades resulting in FE prediction of drying kinetics of many agricultural products.

Nigeria is presently the world's leading producer of cassava (Phillips et al., 2004; FAO, 2008; Akinpelu et al., 2011). Efforts are geared toward promoting the export of the crop and its by-products. Due to the poor storage characteristics of the cassava tuber in its unprocessed state, it is necessary to process the product into a form that is more easily stored in order to minimize deterioration and losses while in transit.

About $88 \%$ of cassava produced in Africa is consumed by humans, 50 percent of which is processed (Famurewa et al, 2014). Freshly harvested Cassava roots cannot be stored for a long period since they rot within 3 to 4 days after harvesting; this means that roots greater than 48 hours old have little market value and limits the range over which fresh roots can be marketed (Famurewa et al, 2014).

Research have proved that drying is the most effective and practical means of reducing post-harvest losses in all agricultural products (fruits, vegetables, tubers etc.). Such losses are due to the lack of proper processing and inadequate storage facilities. It has been estimated that in developing countries, losses range between 30 and 40\% (Jayaraman and Gupta 1995). In addition, the demand for the year-round availability of seasonal food commodities has increased (Jayaraman and Gupta 1995). There is thus a pressing need to match increased production with efficient, suitable, simple, inexpensive and effective post-harvest preservation technique to minimize loss and ensure the supply and availability of food nutrients. To maintain the needed equilibrium balance between food supply and population growth, there is need to ensure that food losses during production time is reduced to the barest minimum. 
Drying behaviour is basically influenced by a number of internal characteristics and thermo physical properties (such as density, permeability, porosity, sorption-desorption) and external parameters (such as temperature, velocity, and relative humidity of the drying medium) (Kaya et al., 2007). Drying kinetics of food crops is generally affected by factors which include drying temperature, pretreatment method, relative humidity, and product sizes (Ade-Omowaye et al., 2002; Kudra, 2004) and are crop specific.

Akpinar et al., (2003 a \& b), Babalis and Belessiotis, (2004), Goyal et al., (2007) reported that physical and thermal properties of agriculture products such as heat and mass transfer, moisture diffusion, energy of activation, and energy consumption are required for ideal dryer design. The drying kinetics for cassava chips need to be determined in order to stabilize variation in the quality of dried cassava chips. For these reasons, as well as the fact that most previous research on drying has concentrated on low air temperatures, this study considers the feasibility of using high temperatures for the drying of cassava pellets. Though, still within the recommended temperature range of drying diascoras. The methodology employed would provide knowledge to Mathematical modelling of cassava drying processes and equipment, which is an important aspect of drying technology; its purpose is to allow design engineers to choose the most suitable operating conditions, size of the drying equipment and drying chamber accordingly to meet desired operating conditions.

Review of literature showed that FE modelling of cassava drying kinetics has not received the attention of the research community. Of all food crops in Nigeria, cassava is the best candidate for such attention since it is the most produced and consumed food crop in Nigeria, especially in the central and southern parts: about $90 \%$ of cassava produced in Nigeria is processed into food (mostly garri)(Ozoegwu, Eze, Onwosi, Mgbemene, \& Ozor, 2017). Considering the enormity of cassava needing drying in Nigeria, experimental and empirical approaches which would need to consider cassava species and drying conditions on case-by-cases basis will be very costly for the industry. Thus there a compelling need for computer simulation of cassava drying. This is the aim pursued in this work using the FE method.

\section{MATERIALS AND METHODS}

\section{A. Experimental process}

A scheme of the cassava samples is presented in Figures 1 for unsteady two-dimensional mass transfer during convective drying. The theoretical or numerical modeling and simulation to be developed will be validated by experimental work that was carried out for different drying parameters of heater temperatures $\left(150^{\circ} \mathrm{C}, 140^{\circ} \mathrm{C}, 130^{\circ} \mathrm{C}, 120^{\circ} \mathrm{C}, 110^{\circ} \mathrm{C}\right)$ which gave corresponding hot air temperatures $\left(81^{\circ} \mathrm{C}, 78^{\circ} \mathrm{C}, 75^{\circ} \mathrm{C}\right.$, $70^{\circ} \mathrm{C}$, and $65^{\circ} \mathrm{C}$ ) and hot air velocities $4 \mathrm{~m} / \mathrm{s}$ at a constant relative humidity as adapted from Azaka et al, 2019.

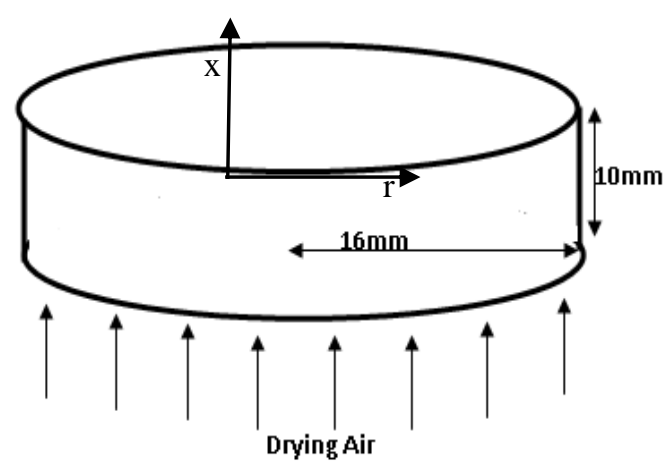

Fig. 1: Schematic diagram of the circular geometry of the cassava slice

\section{B. Thermophysical Characterization of Cassava Samples} As earlier stated, 2-dimensional elements are popular in FE modelling of drying process of agricultural products. Drying is synonymous with water diffusion thus it is a mass transfer process governed by Fick's second law which for the 2dimensional element reads

$$
\begin{aligned}
& \frac{\partial M}{\partial t}=\operatorname{Div}\left[D_{\text {eff }}(T) \operatorname{grad}(M)\right]=D_{\text {eff }}(T)\left(\frac{\partial^{2} M}{\partial x^{2}}+\right. \\
& \left.\frac{\partial^{2} M}{\partial y^{2}}\right)
\end{aligned}
$$

The drying dynamics dictated by equation (1) are influence by both initial condition and Neumann boundary condition. The initial condition is given as $M(t=0)=M_{0}$ while the Neumann boundary condition is given as

$-D_{\text {eff }}(T) \frac{\partial M}{\partial n}=h_{m}(T, t)\left[M_{\text {surf }}-M_{e q}\right]$

Where Msurf represents the surface moisture content and Meq represents the equilibrium moisture content which is a function of seasonal and climatic conditions. In what follows, the 2-dimensional FE formulation for drying of rectangular shaped potatoes as presented in (Beigi, 2017) is adapted here for drying of cassava pellets with circular shapes.

\section{The Effective Diffusivity}

Looking at the boundary condition given in equation (2), it is seen that $D_{\text {eff }}(T)$ and $h_{m}(T, t)$ are necessary for numerical solution of FE analysis. The Crank's series solution for variation with time of moisture ratio for an infinite slab is

$$
M R=\frac{8}{\pi^{2}} \sum_{n=0}^{\infty} \frac{1}{(2 n+1)^{2}} \exp \left(-\frac{(2 n+1)^{2} \pi^{2} D_{\text {eff }} t}{4 H^{2}}\right)
$$

where $H$ is half thickness of the sample and moisture ratio $\mathrm{MR}$ is given as 


$$
M R=\frac{M-M_{e q}}{M_{0}-M_{e q}}
$$

The first term of the series can give acceptable results for long drying periods

$$
M R=\frac{8}{\pi^{2}} \exp \left(-\frac{\pi^{2} D_{\text {eff }} t}{4 H^{2}}\right)
$$

In logarithmic form, Equation (5) becomes

$$
\ln (M R)=\ln \left(\frac{8}{\pi^{2}}\right)-\frac{\pi^{2} D_{\text {eff }}}{4 H^{2}} t
$$

By plotting $\ln (M R)$ against $t$, a straight line is obtained with the slope $S=-\frac{\pi^{3} D_{\text {eff }}}{4 H^{2}}$ such that $D_{\text {eff }}=-\frac{4 H^{2}}{\pi^{2}} S$.

\section{Finite Element Formulation}

In carrying out the Finite Element formulations, the following assumptions stated by (Azaka et al, 2019) were employed:

* No heat is generated inside the sample during the drying process

* Two dimensional equations sufficiently describe the process for small thickness of the drying samples,

* Initial moisture content inside the sample is homogeneous,

* Material to be dried is isotropic

* Shrinkage is neglected.

\section{E. Heat and mass transfer equations}

The two dimensional heat conduction equation in the $\mathrm{x}-$ and $\mathrm{r}$ directions may be written as

$\frac{\partial T}{\partial t}=\alpha\left[\frac{1}{r} \frac{\partial T}{\partial r}+\frac{\partial^{2} T}{\partial r^{2}}+\frac{\partial^{2} T}{\partial x^{2}}\right]+\frac{u^{*}}{\rho c}$

Where $\mathrm{u}^{*}$ is the rate of heat generation per unit volume in the sample. Similarly, the mass transfer equation is written as

$\frac{\partial M}{\partial t}=\operatorname{Deff}\left[\frac{1}{r} \frac{\partial M}{\partial r}+\frac{\partial^{2} M}{\partial r^{2}}+\frac{\partial^{2} M}{\partial x^{2}}\right]+\frac{u^{*}}{\rho c}$

Where Deff is the effective moisture diffusivity. The thermophysical properties in the equations are for the sample being dried.

\section{Initial conditions}

Initially, the slice is at a known uniform temperature and moisture content. Hence,

$$
\mathrm{T}=\mathrm{T}_{0}, \quad \mathrm{t}=0
$$$$
\mathrm{M}=\mathrm{M}_{0, \mathrm{t}} \mathrm{t}=0
$$

\section{Boundary conditions}

At the center of the slice, there must be continuity. Hence, we have

$\frac{\partial T}{\partial r}=0, \quad r=0$

$\frac{\partial M}{\partial r}=0, \quad r=0$

At the periphery, there is forced convection heat exchange with the flowing hot air. Hence, we have

$-\left.k \frac{\partial T}{\partial_{r}}\right|_{r=r_{0}}=h\left(T-T_{a}\right)$

On the other hand, for the mass transfer, we have
$-\left.\operatorname{Deff} \frac{\partial M}{\partial_{r}}\right|_{r=r_{0}}=h m\left(M-M_{e}\right)$

Where $\mathrm{hm}$ is the mass transfer coefficient based on the equilibrium moisture content, Meq.

The boundary conditions in the $\mathrm{x}$-direction are

$-\left.k \frac{\partial T}{\partial_{x}}\right|_{x=0}=h\left(T-T_{a}\right)$

$-\left.\operatorname{Deff} \frac{\partial M}{\partial_{x}}\right|_{x=0}=h m\left(M-M_{e}\right)$

At $\mathrm{x}=\mathrm{L}_{\mathrm{x}}$, the boundary conditions are

$$
\begin{aligned}
& -\left.k \frac{\partial T}{\partial_{x}}\right|_{x=L_{x}}=h\left(T-T_{a}\right) \\
& -\left.\operatorname{Deff} \frac{\partial M}{\partial_{x}}\right|_{x=L_{w}}=h m\left(M-M_{e}\right)
\end{aligned}
$$

\section{RESULTS AND DISCUSSIONS}

\section{A. The Effective Diffusivity}

The plots are shown in Figures 1 to 5 for the experimental drying of the circular samples as discussed under the experimental procedure (Azaka et al, 2019). The plots for the five considered heater temperatures exhibited expected trends; lines with negative slopes. The slopes are seen on the inserted linear equations which are lines of best fit from linear regression. The calculated $D_{\text {eff }}$ are given in Table 1. Also, based on the experimental measurements, the equilibrium moisture content at different times of the days the experiments were conducted are tabulated in Table 1 alongside the heater temperatures employed for experiments.

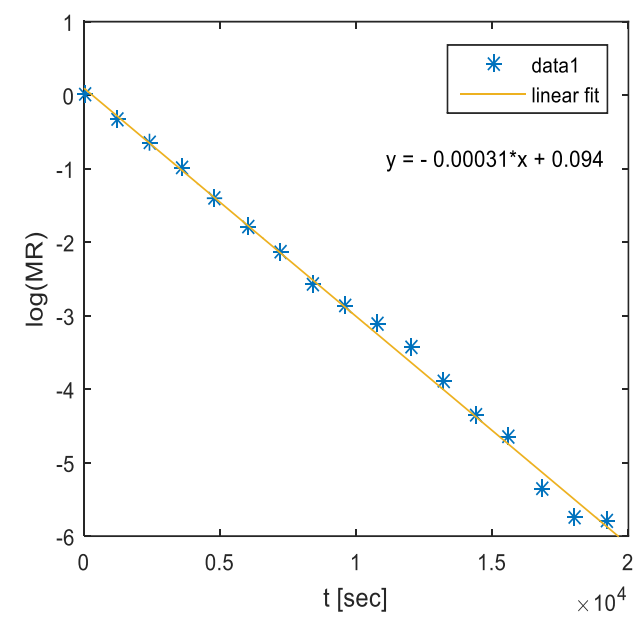

Figure 1. The plot of $\ln (M R)$ against $t$ for the Experiment at Heater Temperature of $150^{\circ} \mathrm{C}$ for the circular samples 


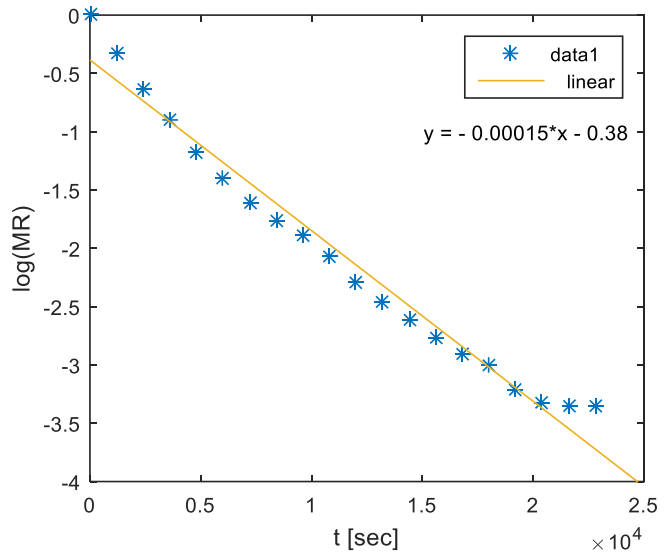

Figure 2. The plot of $\ln (M R)$ against $t$ for the Experiment at Heater Temperature of $140^{\circ} \mathrm{C}$ for the circular samples

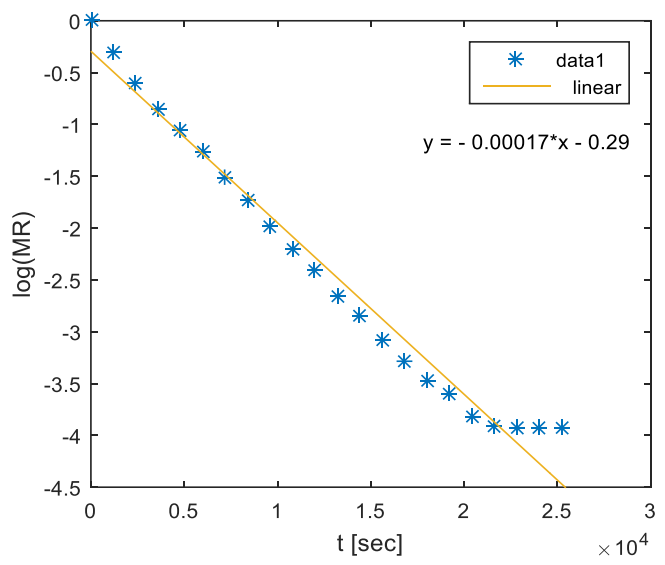

Figure 3. The plot of $\ln (M R)$ against $t$ for the Experiment at Heater Temperature of $130^{\circ} \mathrm{C}$ for the circular samples

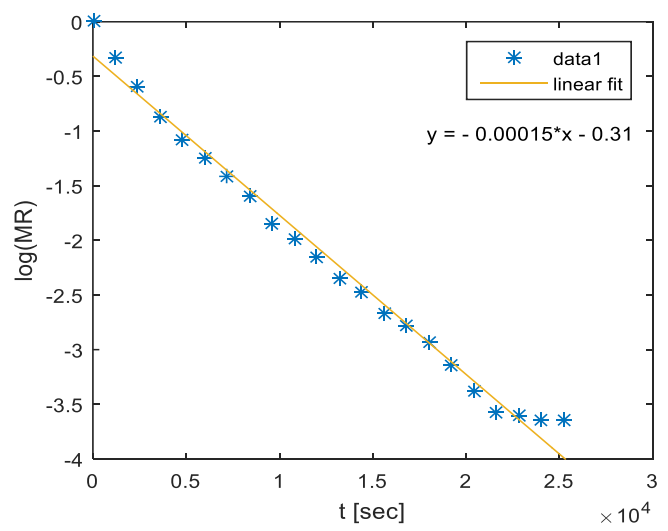

Figure 4. The plot of $\ln (M R)$ against $t$ for the Experiment at Heater Temperature of $120^{\circ} \mathrm{C}$ for the circular samples

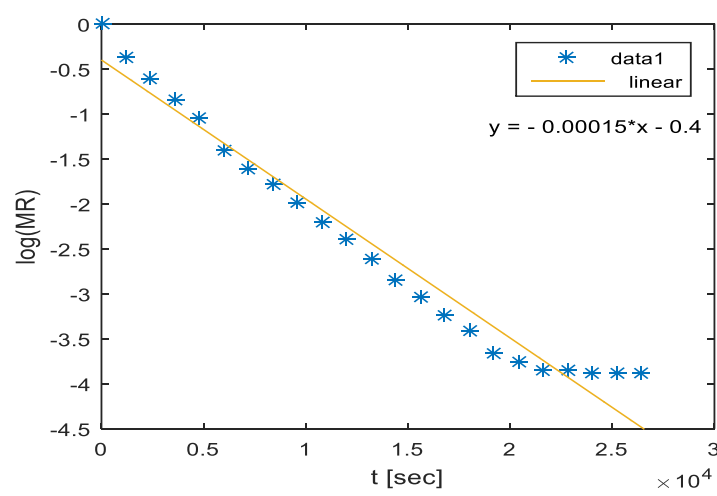

Figure 5. The plot of $\ln (M R)$ against $t$ for the Experiment at Heater Temperature of $110^{\circ} \mathrm{C}$ for the circular samples The diffusivity of the circular samples were determined to be in range of $3.1467 \times 10^{9}-1.4759 \times 10^{9} \mathrm{~m}^{2} \mathrm{~s}^{-1}$, and described using a $3^{\text {rd }}$ order polynomial equation $\left(y=0.0001 x^{3}-0.0487 x^{2}-6.0254 x+246.05\right)$

as a function of air temperature with the value of $\mathrm{R}^{2}=0.9402$ as shown in figure 6 . The plots clearly explains that the moisture diffusivity of cassava pellets can be expressed as a function of temperature using a $3^{\text {rd }}$ order polynomial equation. Diffusivity range and plots follows the same trend with Beigi 2017.

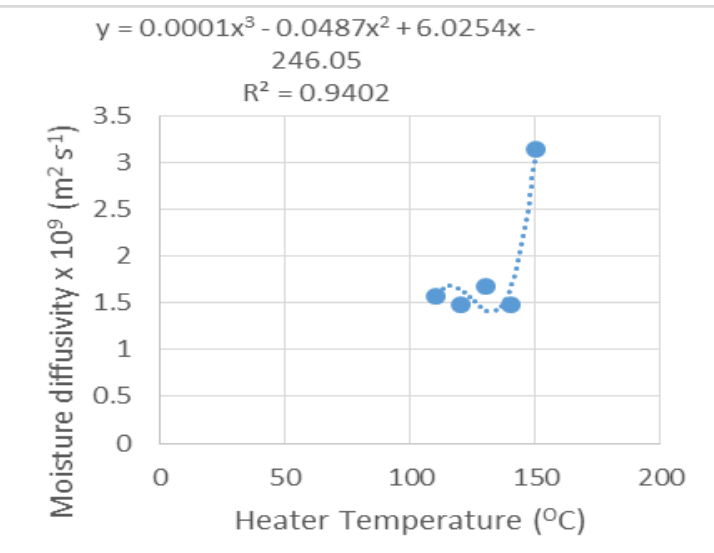

Fig. 6: Air temperature effect on effective moisture diffusivity for the Circular shape cassava pellets.

Table 1. The effective diffusivity at various heater temperatures for the circular samples

\begin{tabular}{|c|c|c|}
\hline \multicolumn{3}{|c|}{ TMS 30572 Circular Samples } \\
\hline $\begin{array}{c}\text { Heater Temperature } \\
{\left[{ }^{\circ} \mathrm{C}\right]}\end{array}$ & $M_{\text {eq }}$ & $D_{\text {eff }} \times 10^{9}$ \\
\hline 150 & 0.5375 & 3.1467 \\
\hline 140 & 0.8375 & 1.4830 \\
\hline 130 & 0.7375 & 1.6770 \\
\hline 120 & 0.9375 & 1.4759 \\
\hline 110 & 1.2375 & 1.5665 \\
\hline
\end{tabular}




\section{International Journal of Engineering Applied Sciences and Technology, 2020 \\ Vol. 4, Issue 11, ISSN No. 2455-2143, Pages 1-7 \\ Published Online March 2020 in IJEAST (http://www.ijeast.com)}

\section{A. Numerical Solutions}

Referring back to the PDE model in Equation (1) for moisture diffusion, the Neumann boundary condition in Equation (2) and the initial condition is the initial moisture content $M_{0}$ which is assumed uniform at $t=0$, numerical solutions are generated from MATLAB programming of the developed models.

For the circular samples drying at $150^{\circ} \mathrm{C}$, the experimental results of corresponding equilibrium moisture content, effective diffusivity, and convective mass transfer coefficient were inserted in the equations $(15,16,17$ and 18). Since these equations is a hybrid formulation of finite element and finite difference methods, the initial condition $M_{0}=3.8871$ is inserted from which the solution propagates. A very accurate moisture content kinetics is predicted as judged with $R^{2}=0.9870, R M S E=0.0853$ and $r=0.9969$. The graphical comparison of the predicted and measured kinetics are presented in Figure 7. At the other experimental temperatures, the predicted solutions agree with experimental solutions with a striking accuracy, especially for the experimental temperatures at $120{ }^{\circ} \mathrm{C}$ and $110{ }^{\circ} \mathrm{C}$. The corresponding comparative graphical results are presented in Figures 8 to 11. Figure 10 depicts the very accurate FE prediction, reflecting the very reliable indices $R^{2}=0.9954, R M S E=0.0409$ and $r=0.9989$, for the experimental drying at $120^{\circ} \mathrm{C}$. Prediction accuracy improved with mesh refinement as seen in Figures 12 to 15 . It is seen that in Figure 12 with 142 elements, the range of solution values as indicated in the colour map/bar is clearly outside the measured moisture values. A color bar provide a map of the different shades to the numerical values of the solution. When the number of elements increased to 539 elements as in Figure 13, the solution values indicated in the colour map showed improvement towards the experimental range for moisture content. Improvements continued with mesh refinement to 2095 element and 8255 elements as respectively seen in Figures 14 and 15 towards the experimental values. The parameters for the solutions and the goodness-of-fit parameters are summarized in Table 2.

These results show that the finite element method can predict cassava drying with a high degree of accuracy such that the costly case-by-case empirical approach, which is based on linear or non-linear regression analysis for parameter estimation, can be avoided.

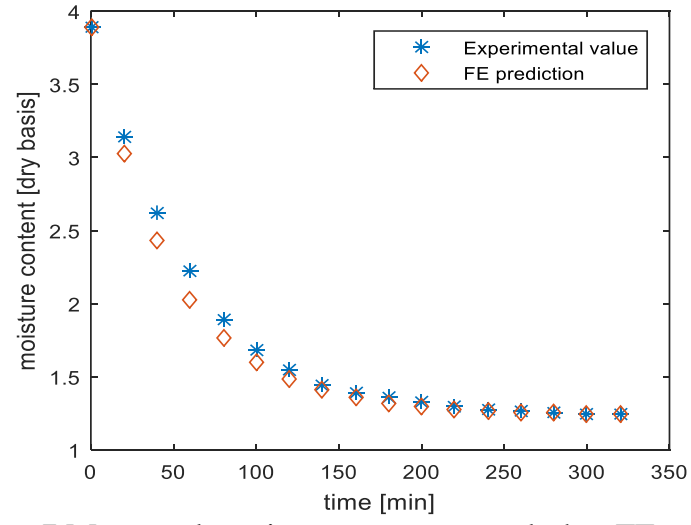

Figure 7.Measured moisture content and the FE predicted moisture content at heater temperature of $150^{\circ} \mathrm{C}$ for the circular cassava sample

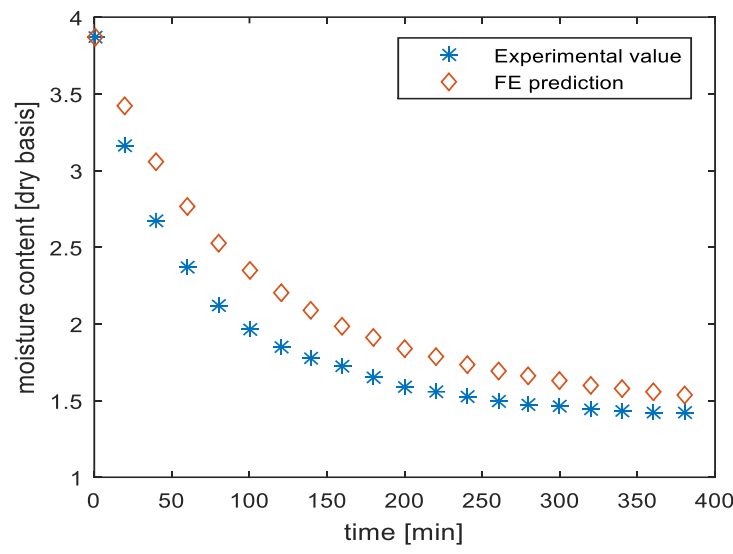

Figure 8.Measured moisture content and the $\mathrm{FE}$ predicted moisture content at heater temperature of $140^{\circ} \mathrm{C}$ for the circular cassava sample

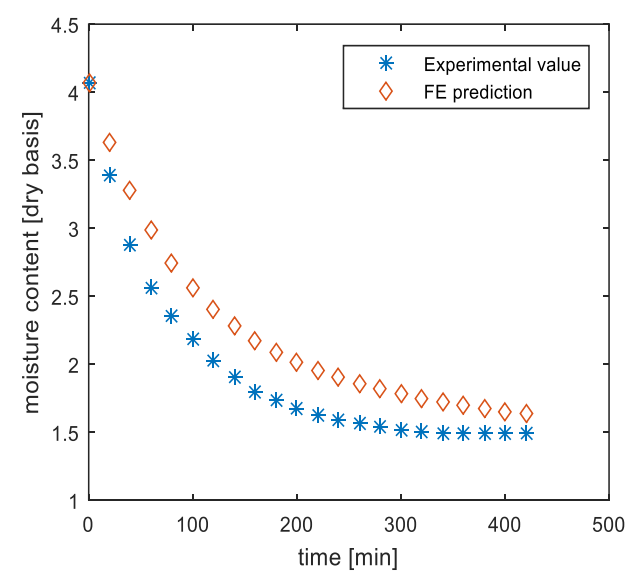

Figure 9.Measured moisture content and the $\mathrm{FE}$ predicted moisture content at heater temperature of $130^{\circ} \mathrm{C}$ for the circular cassava sample 


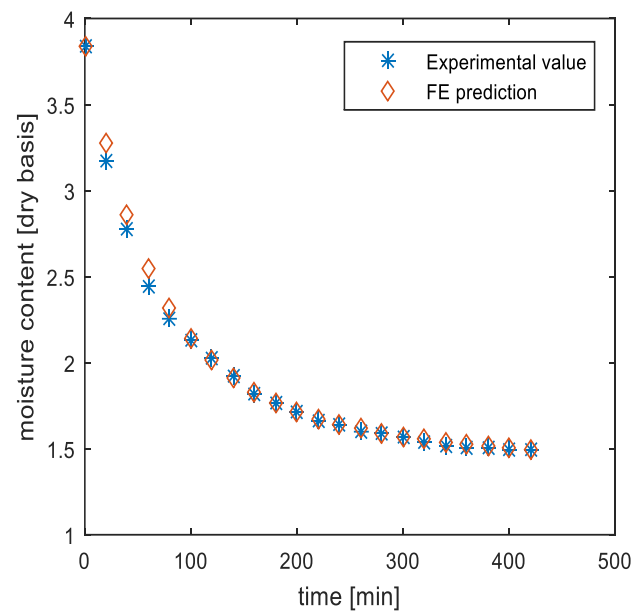

Figure 10.Measured moisture content and the $\mathrm{FE}$ predicted moisture content at heater temperature of $120^{\circ} \mathrm{C}$ for the circular cassava sample

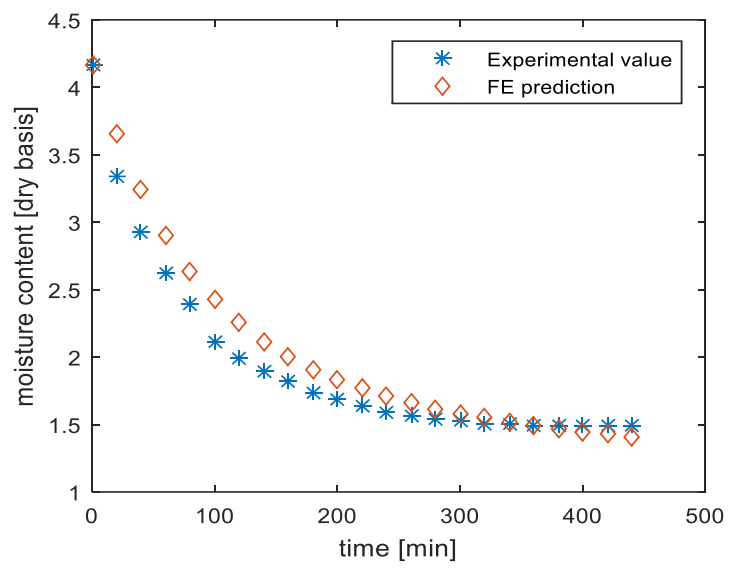

Figure 11.Measured moisture content and the $\mathrm{FE}$ predicted moisture content at heater temperature of $110^{\circ} \mathrm{C}$ for the circular cassava sample

Table 2. The statistical performance indices of the finite element prediction of cassava drying relative to the experimental measurements for the circular pellets

\begin{tabular}{|c|l|l|l|c|}
\hline \multicolumn{5}{|c|}{ Circular Samples } \\
\hline $\mathrm{T}\left[{ }^{\circ} \mathrm{C}\right]$ & $\begin{array}{l}M_{\text {eq }} \\
M_{0}\end{array}$ & $R^{2}$ & $R M S E$ & $r$ \\
\hline 150 & 1.2402 & 0.9870 & 0.0853 & 0.9969 \\
& 3.8871 & & & 0.9866 \\
\hline 140 & 1.3369 & 0.8316 & 0.2634 & \\
& 3.8703 & & & \\
\hline 130 & 1.4377 & 0.7976 & 0.3058 & 0.9889 \\
\hline 120 & 4.0716 & & & \\
\hline 1104367 & 0.9954 & 0.0409 & 0.9989 \\
& 3.8412 & & & \\
\hline & 1.4359 & 0.9341 & 0.1754 & 0.9882 \\
\hline
\end{tabular}

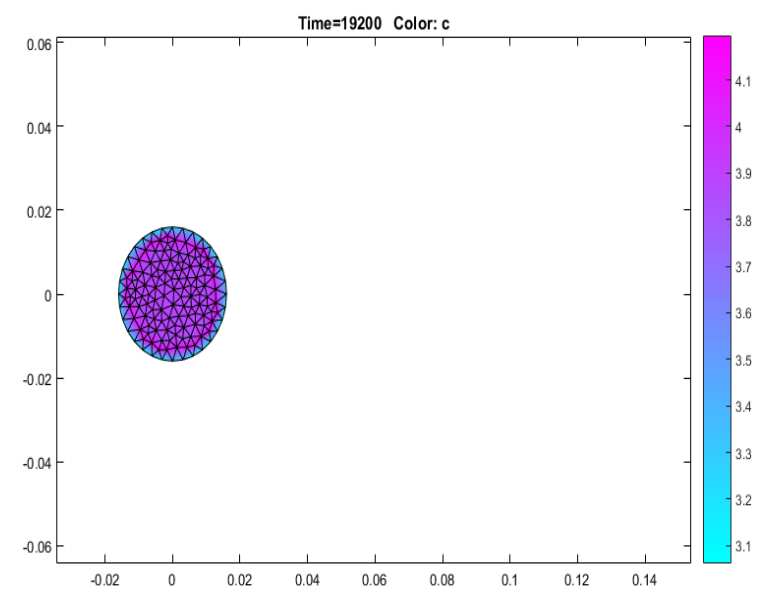

Figure 12. Solution showing the colour bar for 142-Finite Element model

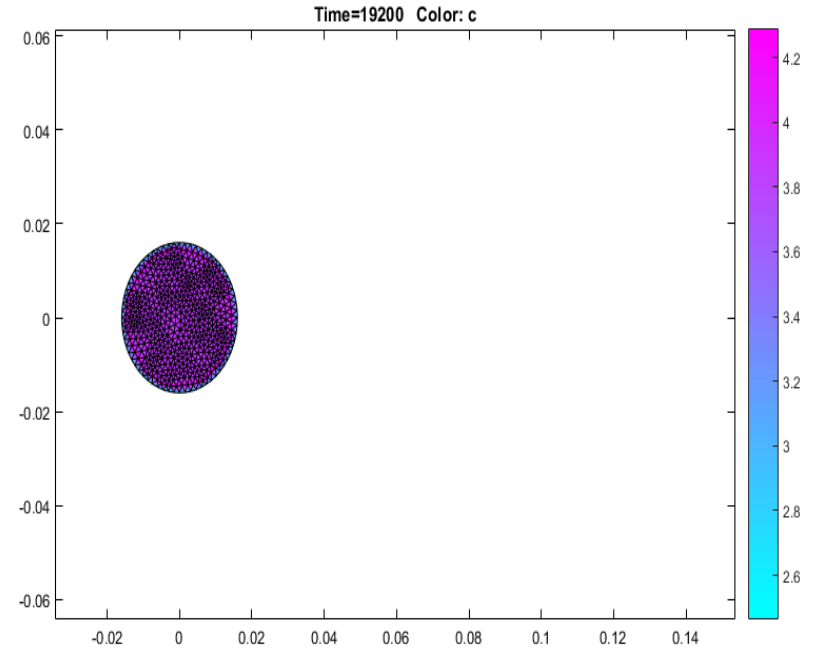

Figure 13. Solution showing the colour bar for 539-Finite Element model

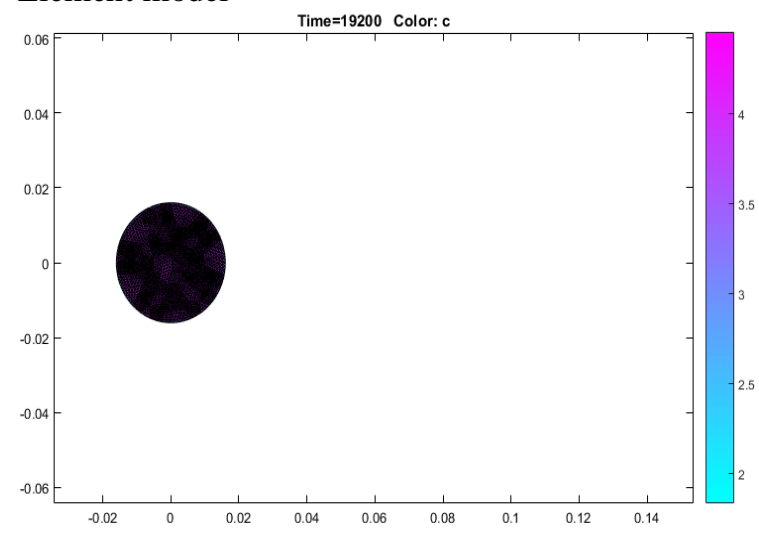

Figure 14. Solution showing the colour bar for 2095-Finite Element model 


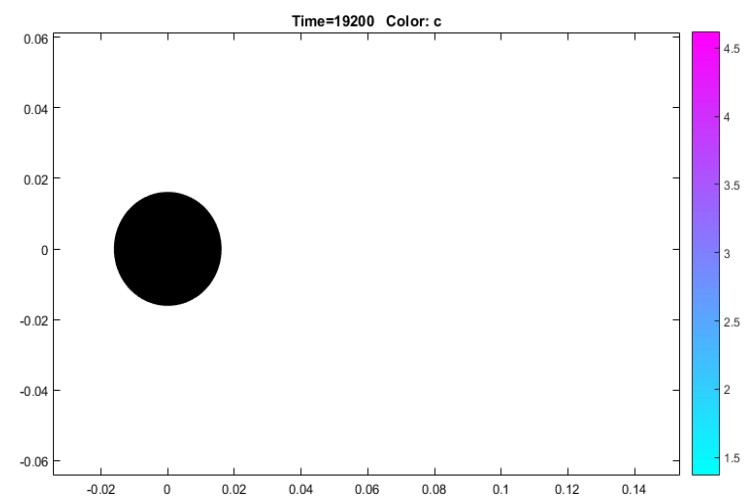

Figure 15. Solution showing the colour bar for 8255-Finite Element model

\section{CONCLUSION}

In this study, convective drying of Cassava Pellets was investigated experimentally and numerically. A twodimensional finite element model programmed in MATLAB version 7.7.0 (R2008b) to simulate the process and predict the drying curves. Drying rate, moisture diffusivity and mass transfer coefficient of the samples were found to increase with the increment in drying air temperature. No constant rate period was seen and the entire drying process of the cassava occurred in the falling rate period at the applied air temperatures. The diffusivity of the samples were determined to be in range of $3.1469 \times 10^{9}-1.5665 \times 10^{9} \mathrm{~m}^{2} \mathrm{~s}^{-1}$ for the circular pellets and were perfectly described using a $3^{\text {rd }}$ order polynomial as a function of air temperature. For each drying temperature, mass transfer coefficient of the samples were determined experimentally and found to be functions of the process time and moisture removal, respectively.

These results show that the finite element method can predict cassava drying with a high degree of accuracy such that the costly case-by-case empirical approach, which is based on linear or non-linear regression analysis for parameter estimation, can be avoided.

\section{Acknowledgements}

I wish to acknowledge Professor S.O. Enibe, and Professor C.H. for their thorough supervision, suggestions and inputs made in the course of this research. I also wish to thank Engr. Abonyi Matthew of Chemical Engineering Department NAU for assisting in the drying processes.

\section{REFERENCE}

[1] Akinpelu, A.O. Amamgbo L.E.F, Olojede A.O, Oyekale A.S. (2011). Health Implications of Cassava Production and Consumption. Journal of Agriculture and Social Research (JASR) Vol. 11, No. 1.

[2] Akpinar E. K., Bicer Y. and Midilli A. (2003). Modeling and experimental study on drying of apple slices in a convective cyclone dryer, Journal of Food Process Engineering, 26 (6) (2003) 515-541.

[3] Azaka Onyemazuwa Andrew, Enibe Samuel Ogbonna, Achebe Chinonso Hubert (2019). Determination of Moisture Diffusivity during Drying of Rectangular Cassava Pellets: Experimental and Modeling Study. Journal of Engineering and Applied Sciences, Volume 15, Number 1, December 2019, 5663

[4] Babalis S.J, Belessiotis V.G. (2004). Influence of the drying conditions on the drying constants and moisture diffusivity during the thin-layer drying of figs. Journal of Food Engineering; 65: 449-458.

[5] Beigi, Moshen. (2017). Numerical simulation of potato slices drying using a two-dimensional finite element model. Chemical Industry \& Chemical Engineering Quarterly, 23(3), 431-440.

[6] Famurewa J.A.V. and Emuekele P.O. (2014). Cyanide reduction pattern of cassava (Mannihot Esculenta) as affected by variety and air velocity using fluidized bed dryer. African Journal of Food Science Technology. 5(3):75-80

[7] Food and Agricultural Organization (FAO) 2004. Proceedings of the validation forum on the global cassava development strategy, Volume 4. FAO, Rome, 26-28 April 2000 .

[8] Irudayaraj, J., Haghighi, K., \& Stroshine, R. L. (1992). Finite element analysis of drying with application to cereal grains. Journal of Agricultural Engineering Research. http://doi.org/10.1016/0021-8634(92)80084-6

[9] Jayaraman, K. S.; Das Gupta, D. K. (1995). Drying of Fruits and Vegetables. : Mujumdar, S. A. (Edt): Handbook of Industrial Drying (Volume 1). New York: Marcel Dekker, Inc. 1995: 643-690.

[10] Kaya A., Aydin O. Dincer I. (2006). Journal of Heat Mass Transfer, Volume 49, pp. 3094-3103

[11] Ozoegwu, C. G., Eze, C., Onwosi, C. O., Mgbemene, C. A., \& Ozor, P. A. (2017). Biomass and bioenergy potential of cassava waste in Nigeria: Estimations based partly on rurallevel garri processing case studies. Renewable and Sustainable Energy Reviews, 72,625-638. http://doi.org/10.1016/j.rser.2017.01.031

[12] Phillips T.P, Taylor D.S, Sanni L, Akoroda M.O (2004). A cassava industrial revolution in Nigeria; the potential for a new industrial crop. The Global Cassava Development Strategy. IFAD/ FAO, Rome. 